\title{
Basic Theory and Design Method of Variable Shaft Angle Line Gear Mechanism
}

\author{
Yang-zhi Chen $1,{ }^{*}-\mathrm{Chao} \mathrm{He}^{1}$ - Yue-ling Lyu ${ }^{2}$ \\ ${ }^{1}$ South China University of Technology, School of Mechanical and Automotive Engineering, China \\ ${ }^{2}$ Sun Yat-sen University, School of Biomedical Engineering, China
}

In this paper, a novel line gear mechanism is proposed; it is called the variable shaft angle line gear mechanism (VSALGM). VSALGM has two rotational degrees of freedom, one is the rotation of the two gears with a constant transmission ratio, and the other is the relative swing of the two gears shafts. First, a novel contact model of VSALGM composed of one driven contact curve and one driving line teeth working surface (DLTWS) was proposed. With the concept, the basic design equations for VSALGM were derived on the basis of the space curve meshing theory of line gear. Moreover, the design criterion of pressure angle for VSALGM was analysed and proposed on the basis of the contact model. A basic design method for VSALGM was thus developed. A design example was given, and prototypes were manufactured using threedimensional (3D) printing. Kinematic experiments and gear contact spot testing were carried out on a self-made kinematic test rig by the prototypes. The results show that the VSALGM designed in this paper can achieve a continuous, smooth and stable meshing transmission while the shaft angle is continuously changed within its setting range.

Keywords: line gear, variable shaft angle, degree of freedom, pressure angle, space curve meshing theory

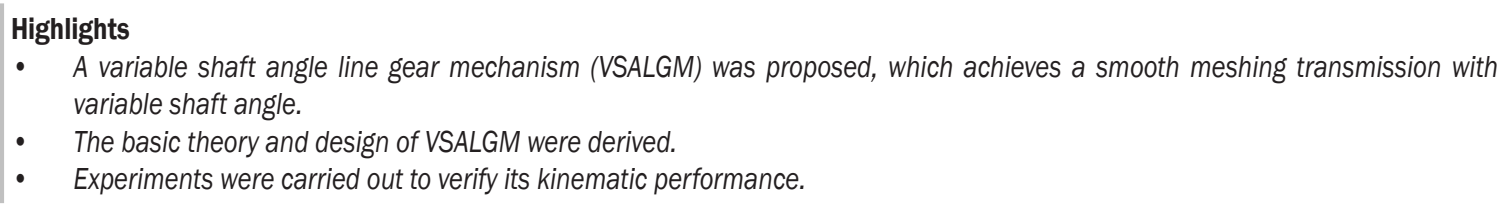

\section{INTRODUCTION}

Conventional gear pairs, including cylindrical gear pairs, bevel gear pairs and, non-cylindrical gear pairs, have a fixed shaft angle, meaning that they have only one rotational degree of freedom while working. Some applications, such as angle grinder [1], flexible joint [2] and manipulator [3], need the functions of both the constant transmission ratio and the two rotational degrees of freedom, but conventional gear pairs cannot satisfy these demands alone. Those applications [1] to [3] are generally achieved by a series connection of universal joints and gearboxes, because a universal joint has two rotational degrees of freedom, and a gearbox provides a constant transmission ratio. However, the series connection of universal joint and gearbox leads to a large structure and low transmission efficiency. Although involute gear pairs with two rotational degrees of freedom [4] and [5] have been developed, their designs are complex.

A line gear based on the space curve meshing theory [6] and [7] is dissimilar from conventional gear based on the space surface meshing theory [8] to [10]. In theory, two space conjugate curves can guarantee the transmission accuracy of line gear [11]. Common line gear mechanisms, including parallel axes line gear mechanisms [12], intersecting axes line gear mechanisms [13] and skew axes line gear mechanisms [14], have only one rotational degree of freedom; specifically, these common line gear mechanisms have a fixed shaft angle. The feature of common line gear mechanisms is that their driving contact curve and driven contact curve is a couple of space conjugate curves.

Based on the space curve meshing theory, a new line gear mechanism referred to as variable shaft angle line gear mechanism (VSALGM) is proposed. VSALGM has a constant transmission ratio and two rotational degrees of freedom. One of the two rotational degrees of freedom is the rotation of the two gears with a constant transmission ratio, and the other rotational degree of freedom is the relative swing of the two gear shafts.

VSALGM is composed of a pair of driving line gear and driven line gear. Different from common line gear mechanisms, VSALGM has a variable shaft angle. Specifically, VSALGM maintains a continuous, smooth and stable meshing transmission with a constant transmission ratio; its shaft angle can be continuously changed within a range.

For VSALGM, the driving contact curve and the driven contact curve are always a couple of space conjugate curves under different shaft angle, wherein the driving contact curve changes with 
different shaft angles, but the driven contact curve remains unchanged. The set of driving contact curves constitutes a driving line teeth working surface (DLTWS). As long as the accuracy of the DLTWS and the driven contact curve are high, the transmission accuracy of VSALGM will be high. In addition to having the advantages of common line gear mechanisms, such as small size, a number of teeth, and a large transmission ratio, more importantly, VSALGM has the features of variable shaft angle and two degrees of freedom, which can provide a better choice for the design cases on the requirement of both constant transmission ratio and two rotational degrees of freedom. Also, it should be noted that VSALGM can only design to transmit the motion in one direction, either in the clockwise direction $(\mathrm{CW})$ or counter-clockwise direction (CCW), which means there is no reversibility of VSALGM.

In this paper, the basic design equations for VSALGM were established, and the design criterion of pressure angle for VSALGM was proposed. Furthermore, based on the pressure angle rule, a parameters selection method of the basic design equations is given. According to the method, a design example was given, and kinematics experiments were completed. Finally, the gear contact spot testing was carried out.

\section{METHODS}

\subsection{Basic Design Equations for VSALGM}

For VSALGM, the driving line gear and the driven line gear rotate around their axis with a constant angular velocity, respectively; meanwhile, the shaft angle of VSALGM can be continuously changed within a range. The design equations are deduced in the following section.

VSALGM can transmit under different shaft angle; its coordinates system is as shown in Fig. 1.

The design equations for VSALGM are denoted in the space curve meshing coordinates, as shown in Fig. 1. The coordinate system $O-x y z$ is set as a fixed Cartesian coordinate system arbitrarily. The coordinate system $O_{\mathrm{p}}-x_{\mathrm{p}} y_{\mathrm{p}} z_{\mathrm{p}}$ is determined by the position of the coordinate system $O-x y z$. The $x_{\mathrm{p}} O_{\mathrm{p}} z_{\mathrm{p}}$ plane coincides with the $x O z$ plane. The distance from $O_{\mathrm{p}}$ to $z$ axis is denoted as $a_{0}$, the distance from $O_{\mathrm{p}}$ to $x$ axis as $b_{0}$, and the included angle between $z$ axis and $z_{\mathrm{p}}$ axis as $\theta_{\mathrm{z}} \cdot \theta_{\mathrm{z}}$ is the shaft angle, the range of $\theta_{\mathrm{z}}$ is from $0^{\circ}$ to $90^{\circ}$; The designed minimum shaft angle is denoted as $\theta_{\mathrm{z}-\min }$ and the designed maximum shaft angle as $\theta_{\mathrm{z}-\max }$. The gear shaft $z_{a}$ and the gear shaft $z_{b}$ are the shafts of line gear A and line gear B; they are collinear with $z$ axis and $z_{\mathrm{p}}$ axis, respectively. Line gear $\mathrm{A}$ rotates around the $z$ axis for an angle $\varphi_{a}$ by a uniform angular velocity $\boldsymbol{\omega}_{a}$. Line gear B rotates around the $z_{\mathrm{p}}$ axis for an angle $\varphi_{b}$ by a uniform angular velocity $\boldsymbol{\omega}_{b}$. In this paper, line gear A is the driven wheel, line gear B is the driving wheel; curve $C_{1}$ represents the driving contact curve, curve $C_{2}$ represents the driven contact curve; the transmission ratio is denoted as $i$, and $i=\varphi_{b} / \varphi_{a}$.

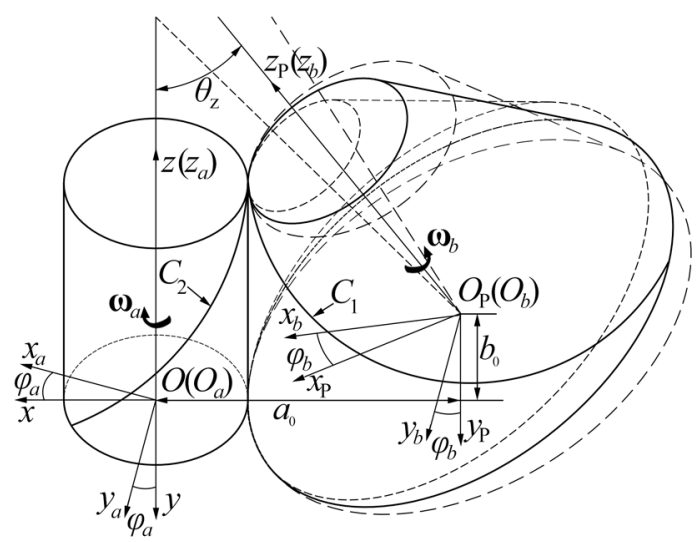

Fig. 1. Space curve meshing coordinates for VSALGM

According to [13], the contact curves of intersecting axes line gears are a couple of space conjugate curves, composed of one cylinder helix curve and one cone helix curve. In this paper, the cone helix curve is defined as the driving contact curve and the cylinder helix curve as the driven contact curve. The equations for the driving contact curve and the driven contact curve are given as Eqs. (1) and (2) in their coordinate systems, respectively.

$$
\left\{\begin{aligned}
x_{\mathrm{M}}^{(b)}= & -\left(\left(m-a_{0}\right) \cos \theta_{\mathrm{z}}+\left(n \pi+n t-b_{0}\right) \sin \theta_{\mathrm{z}}\right) \\
& \times \cos (i t+i \pi) \\
y_{\mathrm{M}}^{(b)} & =\left(\left(m-a_{0}\right) \cos \theta_{\mathrm{z}}+\left(n \pi+n t-b_{0}\right) \sin \theta_{\mathrm{z}}\right), \\
& \times \sin (i t+i \pi) \\
z_{\mathrm{M}}^{(b)}=\left(m-a_{0}\right) \sin \theta_{\mathrm{z}}+\left(n \pi+n t-b_{0}\right) \cos \theta_{\mathrm{z}} & \left\{\begin{array}{l}
x_{\mathrm{M}}^{(a)}=m \cos t \\
y_{\mathrm{M}}^{(a)}=m \sin t, \\
z_{\mathrm{M}}^{(a)}=n \pi+n t
\end{array}\right.
\end{aligned}\right.
$$

where $m$ denotes the helix radius of the driven contact curve; $n$ is the pitch parameter of the driven contact curve, denoting the pitch as $p_{n}, n=p_{n} / 2 \pi ; \theta_{\mathrm{z}}$ is the shaft angle; $t$ is an independent variable, which also indicates the scope of the driven contact curve, that 
$t=[0,2 \pi]$ means a circle of the driven contact curve. The lengths of driving contact curve and driven contact curve are directly controlled by the scope of $t$ on demand.

For VSALGM, its shaft angle is another independent variable. It can be seen from Eq. (1) that different driving contact curves are corresponding to different shaft angles. In other words, there are a series of corresponded driving contact curves when the shaft angle is continuously changed in a certain range. Accordingly, a DLTWS is constituted by the set of the driving contact curves. The equation for the DLTWS is denoted as Eq. (3) in the coordinate system $O_{\mathrm{p}}-x_{\mathrm{p}} y_{\mathrm{p}} z_{\mathrm{p}}$.

$$
\left\{\begin{aligned}
x_{\mathrm{M}}^{(b)}= & -\left(\left(m-a_{0}\right) \cos \theta_{\mathrm{z}}+\left(n \pi+n t-b_{0}\right) \sin \theta_{\mathrm{z}}\right) \\
& \times \cos (i t+i \pi) \\
y_{\mathrm{M}}^{(b)} & =\left(\left(m-a_{0}\right) \cos \theta_{\mathrm{z}}+\left(n \pi+n t-b_{0}\right) \sin \theta_{\mathrm{z}}\right) \\
& \times \sin (i t+i \pi) \\
z_{\mathrm{M}}^{(b)} & =\left(m-a_{0}\right) \sin \theta_{\mathrm{z}}+\left(n \pi+n t-b_{0}\right) \cos \theta_{\mathrm{z}} \\
\theta_{\mathrm{z}}= & \pi t_{1}
\end{aligned}\right.
$$

where $\theta_{\mathrm{z}}$ denotes the shaft angle of VSALGM, which is an independent variable in this paper, and $t_{1}$ represent the scope parameter of the shaft angle.

It should be indicated that $\theta_{\mathrm{z}}$ is a constant in Eq. (1) but a variable in Eq. (3). The basic design equations for VSALGM are set as Eqs. (2) and (3), respectively.

\subsection{Contact Model for VSALGM}

Based on the above basic design equations, the contact model for VSALGM was established by the Wolfram Mathematica software, as shown in Fig. 2.

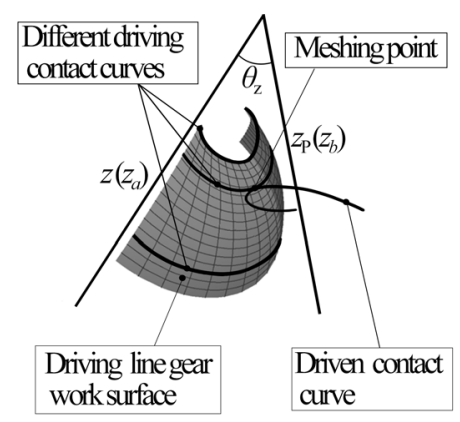

Fig. 2. Contact model for VSALGM

VSALGM can transmit under different shaft angles; its meshing process is similar to the common line gear mechanisms when it transmits under a fixed shaft angle. Different driving contact curves on the DLTWS always mesh with the same driven contact curve, while the shaft angle is continuously changing within the setting range.

Two points need to be explained further. One is that VSALGM can only mesh in one direction, either $\mathrm{CW}$ or $\mathrm{CCW}$. The other is that the two degrees of freedom of VSALGM do not impact each other. The shaft angle can be changed whether the gears rotate or not; and VSALGM can mesh while the shaft angle continuously changing. A constant transmission ratio remains unchanged when the transmission was conducted from the driving wheel to the driven wheel.

\subsection{Analysis of Pressure Angle for VSALGM}

For gears, pressure angle (denoted as $\alpha$ ) has a great influence on the transmission performance: the larger the pressure angle is, the smaller the effective transmission force will be [15]. It is worse for VSALGM that large deformation would be caused by the radial and axial components of the contact force applied on the cantilevered teeth [16]. Even more so, self-lock would be caused by excessive pressure angle, which would make the gear pair unable to be driven. In other words, the value of driving torque must be greater than the value of maximum friction torque for the driven wheel. In this paper, the driving torque is denoted as $M_{a}$, and $M_{a} \leq F m \cos \alpha$, where $F$ denotes the contact force; The maximum friction torque is denoted as $M_{\mu}$, and the static friction coefficient is as $\mu$. In order to avoid self-lock, the value of driving torque must be greater than the value of maximum friction torque, which is that $M_{\mu} \leq \mu F m \leq M_{a} \leq F m \cos \alpha$ [17]. In other words, the value range of pressure angle is as follows: $\alpha \leq \arccos \mu$. Therefore, the allowable value of pressure angle depends on the maximum static friction coefficient of the gear pair. For commonlyused materials of line gear pairs [18], the typical value of the maximum friction coefficient is no greater than 0.7 under the condition of poor or no lubrication [19]. Therefore, the allowable value of pressure angle is derived as follows: $\alpha \leq 45^{\circ}$. Moreover, the design criteria of pressure angle for involute gear and noncircular gear is used as a reference. For the involute gear, the standard pressure angle is equal to $20^{\circ}$ in the China standard [20], and the maximum pressure angle is approximately equal to $45^{\circ}$ when the addendum coefficient is equal to 1 or 0.8 [21]. For the noncircular gear, the maximum pressure angle must be designed to less than $65^{\circ}$ [22]. In summary, the design criterion of pressure angle for VSALGM is as follows: $\alpha \leq 45^{\circ}$. 


\subsection{Parameters Selection Method for VSALGM Based on Pressure Angle Rule}

The value of the pressure angle is determined by the parameters of the basic design equations for VSALGM. The parameters selections are diversified in the basic design equations when designing a pair of line gear. To ensure that the pressure angle is within the allowable range, a parameter selection method was given.

First, the calculation formula for the pressure angle was derived. The pressure angle exists during the transmission between the driving wheel and the driven wheel. The pressure angle is defined as the acute angle between the direction of the contact force and the direction of linear velocity at the meshing point on the driven wheel. The contact form of line gear belongs to point contact. According to the contact model, at the meshing point, the direction of the force for the driven wheel is overlapped with the normal direction of the DLTWS, and the expression of the normal vector of the DLTWS is as Eq. (4).

$$
\mathbf{f}=\left[\begin{array}{ccc}
i_{1} & j_{1} & k_{1} \\
x_{t}^{\prime} & y_{t}^{\prime} & z_{t}^{\prime} \\
x_{\theta_{z}}^{\prime} & y_{\theta_{z}}^{\prime} & z_{\theta_{z}}^{\prime}
\end{array}\right]
$$

In Eq. (4), $i_{1}, j_{1}$ and $k_{1}$ represent the three unit vectors in a Cartesian coordinate system, $x_{t}^{\prime}, y_{t}^{\prime}$ and $z_{t}^{\prime}$ represent the partial derivative of $t, x_{\theta_{z}}^{\prime}, y_{\theta_{z}}$ and $z_{\theta_{z}}^{\prime}$ represent the partial derivative of $\theta_{\mathrm{z}}$.

Next, the parameters are substituted into Eq. (4), at the meshing point, the expression of the normal vector of the DLTWS in the coordinate system $O_{b}-x_{b} y_{b} z_{b}$ can be obtained as Eq. (5).

$$
\mathbf{f}_{b}=\left[\begin{array}{l}
i \cos (i t+i \pi)\left(\left(-a_{0}+m\right) \cos \theta_{\mathrm{z}}-i \sin \theta_{\mathrm{z}}\left(n(t+\pi)-b_{0}\right)\right)^{2}+n\left(n(t+\pi)-b_{0}\right) \sin (i t+i \pi) \\
i n\left(n(t+\pi)-b_{0}\right) \cos (i t+i \pi)-i \sin (i t+i \pi)\left(\left(-a_{0}+m\right) \cos \theta_{\mathrm{z}}-i \sin \theta_{\mathrm{z}}\left(n(t+\pi)-b_{0}\right)\right)^{2} \\
\frac{-i \sin 2 \theta_{\mathrm{z}}-\left(m-a_{0}\right)^{2}+\left(b_{0}-n(t+\pi)\right)^{2}-2 i\left(a_{0}-m\right)\left(b_{0}-n(t+\pi)\right) \cos 2 \theta_{\mathrm{z}}}{2}
\end{array}\right] .
$$

At the meshing point, the expression of the linear velocity for the driven wheel in the coordinate system $O_{a}-x_{a} y_{a} z_{a}$ is as shown in Eq. (6).

$$
\mathbf{v}_{a}=\left[\begin{array}{c}
-m \sin (t) \\
m \cos (t) \\
0
\end{array}\right] .
$$

Eq. (5) can be seen as the expression of the direction of the contact force. To calculate the pressure angle, the expression of the direction of the contact force needs to be converted from the coordinate system $O_{b}-x_{b} y_{b} z_{b}$ to the coordinate system $O_{a}-x_{a} y_{a} z_{a}$. The transformation matrix from the coordinate system $O_{b}-x_{b} y_{b} z_{b}$ to the coordinate system $O_{a}-x_{a} y_{a} z_{a}$ is as shown in Eq. (7).

$\mathbf{M}_{b a}=\left[\begin{array}{cccc}\cos \theta_{z} \cos \varphi_{a} \cos \varphi_{b}-\sin \varphi_{a} \sin \varphi_{b} & \cos \varphi_{a} \sin \varphi_{b}+\cos \theta_{z} \cos \varphi_{b} \sin \varphi_{a} & \cos \varphi_{b} \sin \theta_{z} & -\cos \varphi_{b}\left(b \sin \theta_{z}+a \cos \theta_{z}\right) \\ -\cos \theta_{z} \cos \varphi_{a} \sin \varphi_{b}-\cos \varphi_{b} \sin \varphi_{a} & \cos \varphi_{a} \cos \varphi_{b}-\cos \theta_{z} \sin \varphi_{a} \sin \varphi_{b} & -\sin \theta_{z} \sin \varphi_{b} & \left(-a \cos \theta_{z}+b \sin \theta_{z}\right) \sin \varphi_{b} \\ -\cos \varphi_{a} \sin \theta_{z} & -\sin \theta_{\mathrm{z}} \sin \varphi_{a} & \cos \theta_{z} & -b \cos \theta_{z}-a \sin \theta_{z} \\ 0 & 0 & 0 & 1\end{array}\right]$.

For the driven wheel, the expression of the direction of the contact force in the coordinate system $O_{a}-x_{a} y_{a} z_{a}$ is as follows: $\mathbf{F}_{a}=\mathbf{M}_{b a} \mathbf{f}_{b}$.

Finally, according to the calculation formula for the spatial angle between two vectors, for VSALGM, its calculation formula of the pressure angle is deduced as Eq. (8).

$$
\alpha=\arccos \left[\frac{\left|\mathbf{f}_{a} \mathbf{v}_{a}\right|}{\left|\mathbf{f}_{a}\right|\left|\mathbf{v}_{a}\right|}\right] .
$$

In order to analyse the values and distributions of the pressure angle more intuitively, calculation example 1 was given referring to [13], and the parameters of VSALGM were as follows: $m=12.5$ $\mathrm{mm}, n=6 \mathrm{~mm}, a_{0}=30 \mathrm{~mm}, b_{0}=10 \mathrm{~mm}, i=0.5 \mathrm{~mm}$, $\theta_{\mathrm{z}}=\left[0^{\circ}, 90^{\circ}\right]$ and $t=[0,10]$. In calculation example 1 , the values and distributions of the pressure angle were obtained by using Eq. (8), and the distribution graph was plotted by using Wolfram Mathematica software, as shown in Fig. 3. 


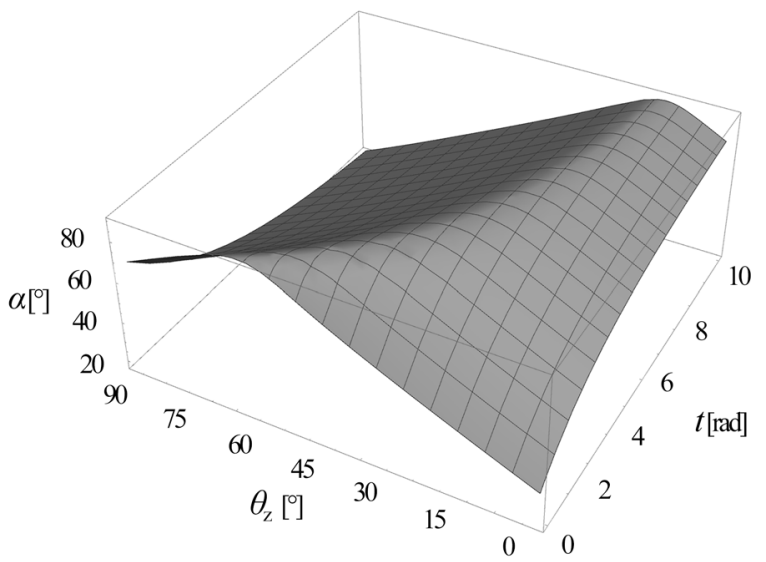

Fig. 3. The pressure angle distribution graph in calculation example 1

It can be seen from Fig. 3 that the pressure angle goes beyond the allowable value in some parameter ranges, which may cause self-lock. Therefore, acceptable design parameters must be chosen to ensure that the pressure angle is always within the allowable range.

Parameters including $m, n, a_{0}$, and $b_{0}$ are usually selected according to the geometric parameters selections of line gear pairs [23], and the transmission ratio $i$ is selected on the requirement of practical design. From Fig. 3, it can be seen that different areas in the pressure angle distribution graphs can be selected by $\theta_{\mathrm{z}}$ and $t$, which means that the pressure angle can be controlled within the allowable range when a reasonable range of $\theta_{\mathrm{z}}$ and $t$ are selected. In general, the value range of $\theta_{\mathrm{z}}$ is determined on the requirement of practical design. The value range of $t$ is chosen under the conditions of that $\alpha \leq 45^{\circ}$ and that the contact ratio of line gear greater than 1 with noninterference [24].

The above analysis shows that the value of pressure angle can be controlled by the selection of the variable $t$. Therefore, the basic design method for VSALGM can be summarized as follows: On the first step, the basic design equations for VSALGM are calculated. On the second step, parameters $i$ and $\theta_{\mathrm{z}}$ are selected on the requirement of practical design; Parameters $m, n, a_{0}$, and $b_{0}$ are selected according to the geometric parameters selections of line gear pairs [23], and parameter $t$ is selected according to the design criterion of pressure angle. On the third step, the 3D models are designed by using the 3D Design Software. In short, the basic design method for VSALGM can be described by the design flow chart in Fig. 4.

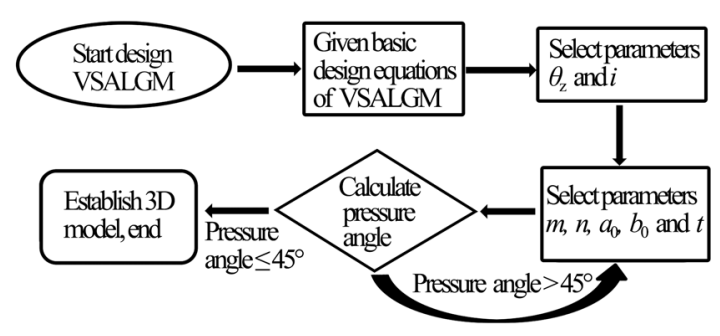

Fig. 4. Design flow Chart for VSALGM

Usually, the driving gear and driven gear are installed in their corresponding position. When the driving gear and driven gear have to swap positions, it is necessary to recalculate whether the pressure angle is within the allowable range or not; the calculation method refers to the above analysis.

\section{EXPERIMENTAL}

\subsection{Design Example 2}

According to the basic design method for VSALGM proposed in Section 1, design example 2 was derived based on calculation example 1. It is necessary to indicate that the range of shaft angle is selected on specific requirements. In design example 2, the original parameters were set as follows: $m=12.5 \mathrm{~mm}$, $n=6 \mathrm{~mm}, \quad a_{0}=30 \mathrm{~mm}, \quad b_{0}=10 \mathrm{~mm}, \quad i=0.5 \mathrm{~mm}$, $\theta_{\mathrm{z}}=\left[75^{\circ}, 90^{\circ}\right]$ and $t=[5,9]$. The pressure angle distribution graph of design example 2 was shown in Fig. 5.

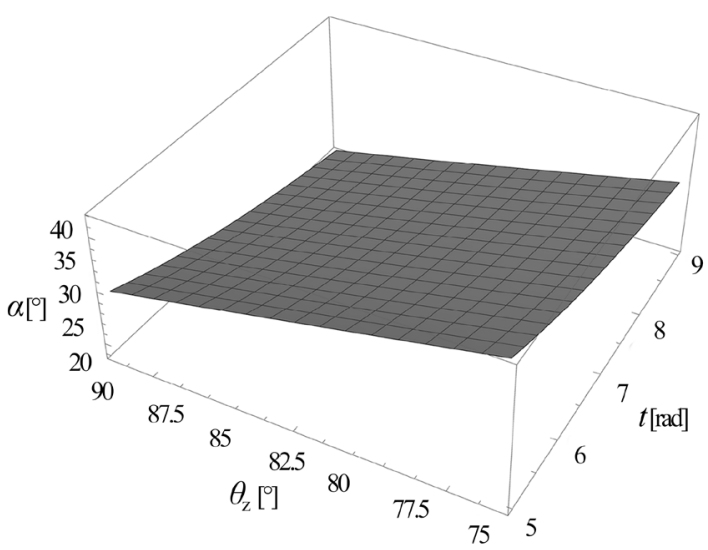

Fig. 5. Pressure angle distribution graph for design example 2

For design example 2, when the relevant parameters are substituted into Eq. (3), the equation for the DLTWS is obtained as Eq. (9). 


$$
\left\{\begin{array}{l}
x_{\mathrm{M}}^{(b)}=\left(17.5 \cos \theta_{\mathrm{z}}+(6 \pi+6 t-10) \sin \theta_{\mathrm{z}}\right) \cos 2 t \\
y_{\mathrm{M}}^{(b)}=-\left(17.5 \cos \theta_{\mathrm{z}}+(6 \pi+6 t-10) \sin \theta_{\mathrm{z}}\right) \sin 2 t . \\
z_{\mathrm{M}}^{(b)}=-17.5 \sin \theta_{\mathrm{z}}+(6 \pi+6 t-10) \cos \theta_{\mathrm{z}}
\end{array}\right.
$$

When the relevant parameters are substituted into Eq. (2), the equation for the driven contact curve is obtained as Eq. (10).

$$
\left\{\begin{array}{l}
x_{\mathrm{M}}^{(a)}=12.5 \cos t \\
y_{\mathrm{M}}^{(a)}=12.5 \sin t \\
z_{\mathrm{M}}^{(a)}=6 \pi+6 t
\end{array}\right.
$$

The tooth model of the driven gear was established by using the Unigraphics NX software. Specifically, a completed DLTWS was fitted and constructed depending on six driving contact curves, which correspond to six shaft angles $\left(74^{\circ}, 78^{\circ}, 82^{\circ}\right.$, $\left.86^{\circ}, 90^{\circ}, 94^{\circ}\right)$. In order to make VSALGM work properly in the theoretical scope, the practical value range of $\theta_{\mathrm{z}}$ is slightly greater than the theoretical scope. The structures of the areas, where the shaft angle is out of the setting scope, only play a role of support, but do not participate in transmission. By using the Unigraphics NX software, the fitted DLTWS and the tooth model were obtained, as shown in Fig. 6 . The six curves on the driving tooth surface in Fig. 6 represent the six driving contact curves of the above design.

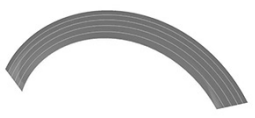

a)

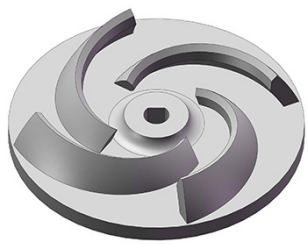

c)

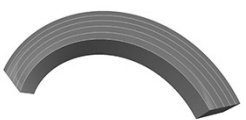

b)

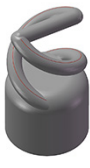

d)
Fig. 6. 3D model of VSALGM; a) fitted DLTWS, b) fitted tooth model, c) driving line gear model, and d) driven line gear model

Fig. 6a shows one driving tooth surface, Fig. $6 \mathrm{~b}$ shows a driving tooth model, Fig. $6 \mathrm{c}$ shows the driving line gear model, and Fig. $6 \mathrm{~d}$ shows the driven line gear model.

According to the construction method of the normal line gear teeth, the driven tooth was generated by the function of ScanTo3D in the SolidWorks software, with the driven contact curve as the boundary and a $5 \mathrm{~mm}$ diameter circle as the outline, as shown in Fig. 6. The designed structure of line gear has a small volume and light weight. The line gear has the characteristic of a small number of teeth. The tooth number of the driving line gear was set as 4 , and the driven line gear as 2 . The completed line gear was obtained by connecting the line gear teeth.

\subsection{Kinematics Experiments for VSALGM}

The prototypes were made by $3 \mathrm{D}$ printing according to the above model, as shown in Fig. 7. According to the product manual, the tolerance of the $3 \mathrm{D}$ printing line gears is 200 microns.

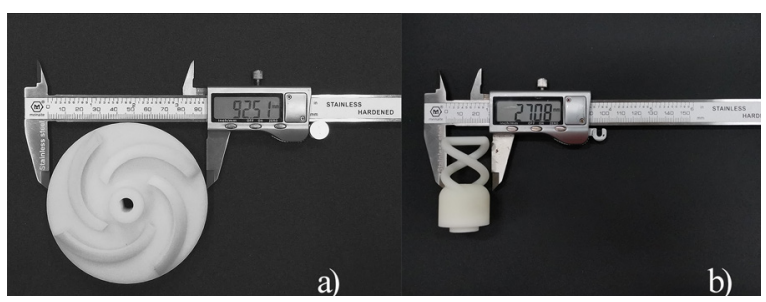

Fig.7. Prototypes of VSALGM: a) driving wheel, and b) driven wheel

It can be seen from Fig. $7 \mathrm{~b}$ that the driven gear consists of a small spiral tooth; therefore, VSALGM can only be used for small loads.

The kinematics performance of VSALGM was verified in the self-made kinematics test rig, as shown in Fig. 8.

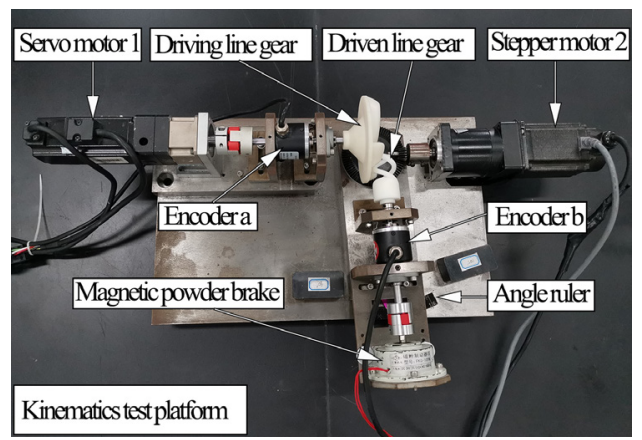

Fig. 8. The test rig for VSALGM

According to [25], kinematics experiments for VSALGM were carried out using the self-made kinematics test rig, as shown in Fig. 8. The two gears were installed. The geared servo motor 1 generated a clockwise motion, and the driving wheel transmitted the motion to the driven wheel. The geared stepper motor 2 generated another motion making the shaft angle be changed. There were two encoders installed on the driving wheel and the driven wheel for 
recording the angular displacements of the two gears, respectively. A magnetic powder brake connected to the driven wheel, which generated the load. The speed and angular displacement of the geared servo motor 1 can be quantitatively controlled through the motion controller installed on a personal computer. The pulse signals of the two encoders (output 20000 pulses per revolution) are obtained by the data acquisition card installed on the personal computer. The angular displacement of each gear can be obtained from the collected pulse signals.

The kinematics experiments were conducted by three groups, and each group included the testing of fixed shaft angle $\left(88^{\circ}, 82^{\circ}\right.$ and $\left.76^{\circ}\right)$ and the testing of continuously changing shaft angle. The three groups were conducted on the condition of different loads. VSALGM is only suited for small loads. Therefore, the load was set as $0 \mathrm{~N} \cdot \mathrm{mm}$ in group $1,30 \mathrm{~N} \cdot \mathrm{mm}$ in group 2 and $60 \mathrm{~N} \cdot \mathrm{mm}$ in group 3. The geared servo motor 1 was set as $1.67 \mathrm{rpm}$. The sampling frequency of the two encoders was set as $20 \mathrm{~Hz}$ in the experiment. The geared stepper motor 2 was set as $0.0347 \mathrm{rpm}$, for continuously changing the shaft angle from $90^{\circ}$ to $75^{\circ}$. The transmission performance of VSALGM varies periodically relating to the number of teeth. In this paper, the driving line gear and the driven line gear rotated 2 revolutions and 4 revolutions, respectively, during the tests, which mean the testing time equal to $72 \mathrm{~s}$.

\subsection{Gear Contact Spot Testing}

In this paper, the red lead powder was used as the developer in the gear contact spot testing to research the contact form of VSALGM. The developer was evenly smeared on the driving gear tooth surface, as shown in Fig. 9. When the two gears are meshed, the developer will stick to the driven wheel from the driving wheel at the contact point, and the developer will be driven away at the contact point because of the contact force. The contact spots on the two gear tooth surfaces can be observed after the two gears meshed.

In the gear contact spot testing, the gear pair was installed on the self-made gear kinematics test rig, and the load was set to $30 \mathrm{~N} \cdot \mathrm{mm}$. The gear contact spot testing was successively conducted under two different shaft angles $\left(82^{\circ}\right.$ and $\left.76^{\circ}\right)$, and the contact spots on the two gears tooth surfaces were obtained.

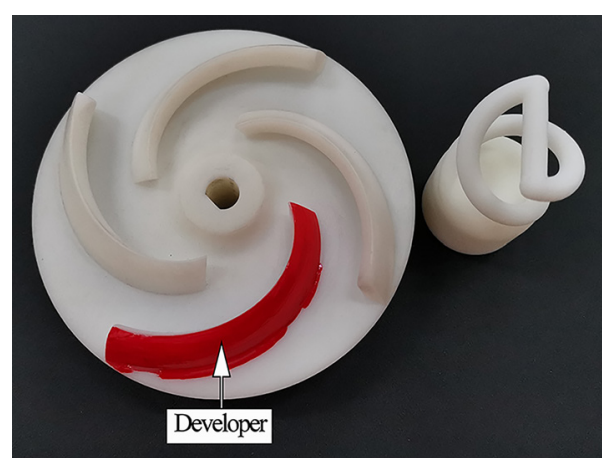

Fig. 9. Diagram of the gear contact spot testing

\section{RESULTS}

In order to study the kinematic performance of VSALGM, the experiments were conducted when the designed gears meshed at different shaft angles. The transmission error is the difference between the real angular displacement and the theoretical angular displacement of the driven line gear shaft [26]. According to [27], the data of the transmission error were measured through the collected encoder's data when the designed gears meshed at different shaft angles, as shown in Figs. 10 to 12.

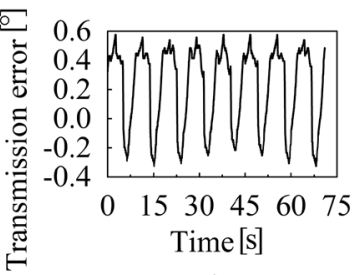

a)

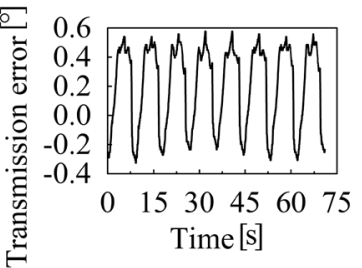

c)

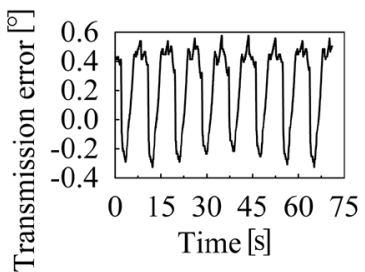

b)

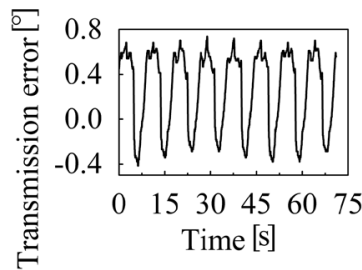

d)
Fig. 10. Measured transmission error curves with load for $0 \mathrm{~N} \cdot \mathrm{mm}$ : a) $\theta_{\mathrm{z}}=88^{\circ}$; b) $\theta_{\mathrm{z}}=82^{\circ}$; c) $\theta_{\mathrm{z}}=76^{\circ}$;

d) $\theta_{\mathrm{z}}$ changing from $90^{\circ}$ to $75^{\circ}$

In Figs. 10 to 12, the four different curves in each figure show the three fixed shaft angle testing results and the changing shaft angle testing result on the condition of different loads. For each transmission error curve, the curve between the bottoms of every two peaks represents 1 tooth rotation, and the bottom of each peak represents the contact conversion 


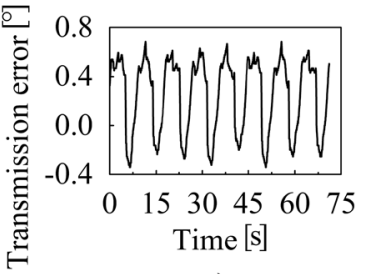

a)

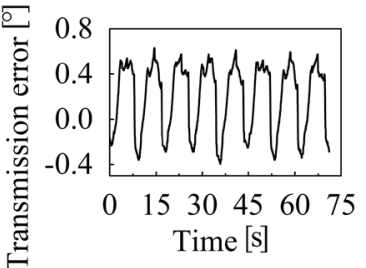

c)

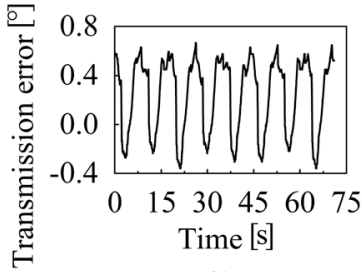

b)

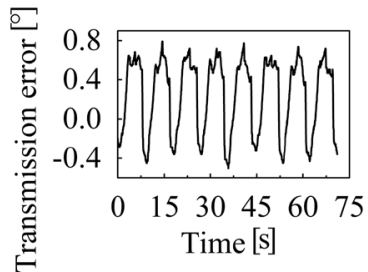

d)
Fig. 11. Measured transmission error curves with load for 30 $N \cdot m m:$ a) $\theta_{\mathrm{z}}=88^{\circ}$; b) $\theta_{\mathrm{z}}=82^{\circ}$; c) $\theta_{\mathrm{z}}=76^{\circ}$; d) $\theta_{\mathrm{z}}$ changing from $90^{\circ}$ to $75^{\circ}$

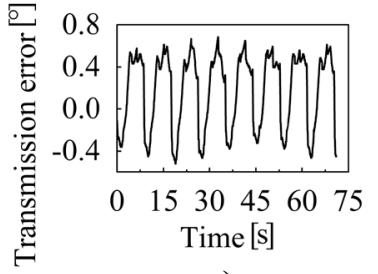

a)

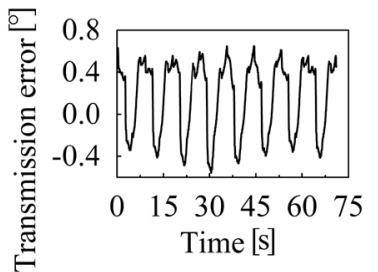

c)

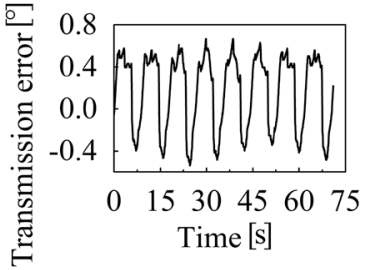

b)

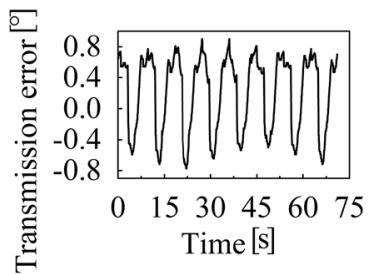

d)
Fig. 12. Measured transmission error curves with load for 60 N.mm: a) $\theta_{\mathrm{z}}=88^{\circ}$; b) $\theta_{\mathrm{z}}=82^{\circ}$; c) $\theta_{\mathrm{z}}=76^{\circ}$; d) $\theta_{\mathrm{z}}$ changing from $90^{\circ}$ to $75^{\circ}$

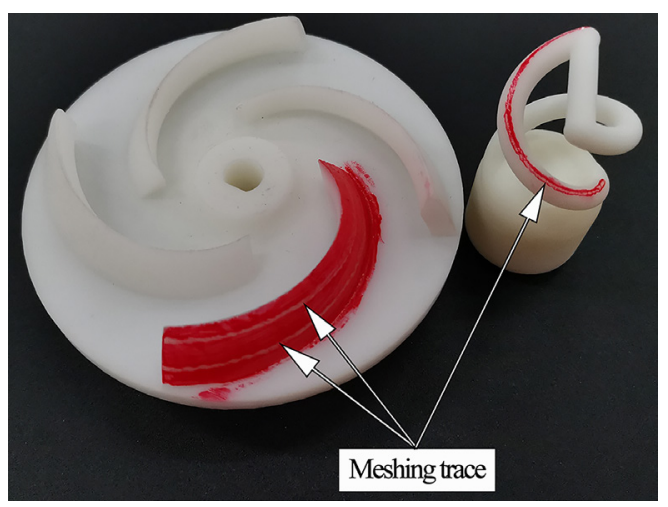

Fig. 13. Results of the gear contact spot testing between two teeth. The transmission errors data analyses are tabulated as Table 1, including the peakto-peak value, amplitude and standard deviation of the transmission error.

In the gear contact spot testing, the meshing traces appeared on both driving line gear and driven line gear after the two gears meshed. The results of the gear contact spot testing were obtained after rotating the gear pair, as shown in Fig. 13.

Table 1. Transmission errors for the kinematics experiments

\begin{tabular}{ccccc}
\hline $\begin{array}{c}\text { Load } \\
{[\mathrm{N} \cdot \mathrm{mm}]}\end{array}$ & $\begin{array}{c}\text { Shaft angle } \\
{\left[{ }^{\circ}\right]}\end{array}$ & $\begin{array}{c}\text { Peak-to-peak } \\
\text { value }\left[{ }^{\circ}\right]\end{array}$ & $\begin{array}{c}\text { Amplitude } \\
{\left[{ }^{\circ}\right]}\end{array}$ & $\begin{array}{c}\text { Standard } \\
\text { deviation }\left[{ }^{\circ}\right]\end{array}$ \\
\hline \multirow{3}{*}{0} & 88 & 0.9 & 0.576 & 0.284 \\
\cline { 2 - 5 } & 82 & 0.9 & 0.576 & 0.284 \\
\cline { 2 - 5 } & 76 & 0.9 & 0.576 & 0.286 \\
\cline { 2 - 5 } & 90 to 75 & 1.152 & 0.738 & 0.357 \\
\hline \multirow{3}{*}{30} & 88 & 1.026 & 0.684 & 0.307 \\
\cline { 2 - 5 } & 82 & 1.026 & 0.666 & 0.308 \\
\cline { 2 - 5 } & 76 & 1.026 & 0.63 & 0.306 \\
\hline \multirow{3}{*}{60} & 90 to 75 & 1.296 & 0.792 & 0.385 \\
\cline { 2 - 5 } & 88 & 1.206 & 0.684 & 0.358 \\
\cline { 2 - 5 } & 82 & 1.206 & 0.666 & 0.356 \\
\cline { 2 - 5 } & 76 & 1.206 & 0.648 & 0.352 \\
\hline & 90 to 75 & 1.674 & 0.9 & 0.494 \\
\hline
\end{tabular}

\section{DISCUSSION}

It can be seen from the kinematics experiments that VSALGM can achieve a continuous, smooth, and stable meshing transmission under the setting range of shaft angle, meaning that VSALGM has two degrees of freedom. The range of shaft angle is selected on specific requirements. In this paper, the range of the shaft angle is from $90^{\circ}$ to $75^{\circ}$, but for other designs, in practically, the range of shaft angle has different options.

It can be seen from Figs. 10 to 12 and Table 1 that the transmission error is a consistent level under different fixed shaft angles on the condition of the same load. However, the transmission error of the testing of continuously changing shaft angle is greater than the testing of fixed shaft angles; it is because of the installation error other than the shaft angle variations. According to the experiment results, the transmission error increases with the increase of the load. Due to the cantilevered teeth, the loads will cause deformations on the teeth of VSALGM, which lead to the errors of the real meshing contact curves and cause the transmission error. Therefore, VSALGM can only conduct transmission under small loads. 
The transmission error of VSALGM in the kinematics experiments is mainly due to the errors of the instrument and the test prototypes, which includes the encoder error, the motor vibration error, the gears installation error and the test prototypes error. The different sources of error were analysed for VSALGM. Theoretically, the gear installation error of VSALGM includes axial error and eccentricity error; it mainly depends on the accuracy of the test rig. For the test rig in Fig. 8, the tolerance of the manufactured parts is $20 \mu \mathrm{m}$, the tolerance of the gear shaft is $10 \mu \mathrm{m}$, the tolerance of the bearing is $10 \mu \mathrm{m}$, and the tolerance of the positioning pin is $10 \mu \mathrm{m}$. A slide calliper rule with an accuracy of $20 \mu \mathrm{m}$ was used to assist the gear installation. Therefore, the gear installation error analysis can be obtained, as shown in Fig. 14.

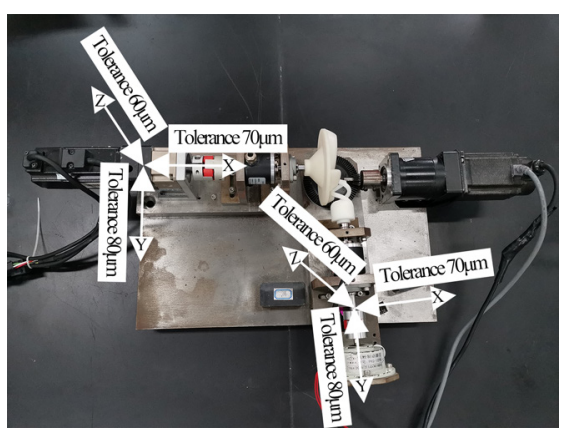

Fig. 14. The gear installation error

As shown in Fig. 14, for the gear installation error, both the axial tolerance and the eccentricity tolerance are about $140 \mu \mathrm{m}$. In addition, the tolerance of the line gear prototypes is $200 \mu \mathrm{m}$, and the deformations on the teeth of VSALGM increases with the load. The accuracy of the encoder is $1.08^{\prime}$. The motor vibration error will cause the driving wheel to rotate reverse instantaneously with a small angle. In this paper, a reducer and an elastic coupling were used to reduce the influence of motor vibration. It is difficult to study the accuracy of the gear installation error based on the above experimental equipment. However, the experiments in this paper focus on verification of the basic theory and design method of VSALGM, which have proved that VSALGM has two degrees of freedom and maintains a smooth transmission while continuously changing the shaft angle. In the future, the precision testing bench and precision line gears will be developed to investigate the transmission error and dynamic performance for VSALGM.

For the gear contact spot testing, it can be seen from Fig. 13 that there are two different meshing traces on the driving tooth surface and only one meshing trace on the driven line gear after the gear pair meshing under the two different shaft angles. The meshing trace on the driven line gear is a cylindrical helix curve under the two different shaft angles. The gear contact spot testing proved that for VSALGM, different driving contact curves always mesh with the same driven contact curve under different shaft angle. The gear contact spot testing also proved that VSALGM belongs to point contact.

Finally, it can be seen from the kinematics experiments and the gear contact spot testing that whether it is a theoretically designed driving contact curve or a fitted driving contact curve, they all can achieve a smooth meshing transmission by meshing with the same driven contact curve.

\section{CONCLUSIONS}

In this paper, a line gear mechanism with two rotational degrees of freedom referred to as Variable Shaft Angle Line Gear Mechanism (VSALGM) is proposed. The main work is summarized as follows:

(1) Based on the space curve meshing theory of line gear, the basic design equations for the proposed VSALGM were established. The design criterion of pressure angle was proposed, and a parameter selection method was given.

(2) The prototypes of VSALGM were manufactured by using $3 \mathrm{D}$ printing. Based on the prototypes, the kinematic experiments for VSALGM were conducted under different shaft angles. The kinematic experiments results have proved that VSALGM has two degrees of freedom and maintains a smooth transmission while continuously changing the shaft angle.

(3) The gear contact spot testing were carried out, which have shown that there are different driving contact curves meshing with the same driven contact curve under different shaft angle for VSALGM.

However, many problems remain to be studied, such as the non-interference between two gears, parameters optimization, structural design, strength formula and sliding ratio for VSALGM, the efficiency and friction losses, the transmission error. More importantly, we will manufacture precision prototypes and develop a practical precision testing bench for testing the integrated performance of transmission for VSALGM in future.

\section{ACKNOWLEDGEMENTS}

The authors gratefully acknowledge the supports from the National Natural Science Foundation of 
China [No. 51575191], Natural Science Foundation of Guangdong Province [No. 2018A030310404] and 2019 Guangzhou technology project [No.201904010368]. It is our honour to thank the reviewers and editors for their valuable criticisms and comments.

\section{NOMENCLATURES}

$a_{0} \quad$ The distance from point $O_{\mathrm{p}}$ to $z$ axis

$b_{0} \quad$ The distance from point $O_{\mathrm{p}}$ to $x$ axis

$m$ The helix radius of driven contact curve

$n \quad$ A pitch parameter of driven contact curve

$\theta_{z} \quad$ The shaft angle of VSALGM

$i \quad$ The transmission ratio

$t$ The scope parameter of helix curve

$\varphi_{a}$ The rotation angle of driven wheel

$\varphi_{b} \quad$ The rotation angle of driving wheel

$\boldsymbol{\omega}_{a}$ The angular velocity of driven wheel

$\boldsymbol{\omega}_{b}$ The angular velocity of driving wheel

$F$ The value of contact force

$M_{a}$ The value of driving torque

$M_{\mu}$ The value of maximum friction torque of line gear

$\mu \quad$ The static friction coefficient of line gear pair

$\alpha$ The pressure angle

$\mathrm{f}_{b}$ The normal vector in the coordinate system $O_{b}-x_{b} y_{b} z_{b}$ at the meshing point

$\mathbf{v}_{a}$ The linear velocity of driven gear at the meshing point

$\mathbf{M}_{b a}$ The transformation matrix from $O_{b}-x_{b} y_{b} z_{b}$ to $O_{a}-x_{a} y_{a} z_{a}$

\section{REFERENCES}

[1] Reinvee, M., Aia, S., Pääsuke, M. (2019). Ergonomic benefits of an angle grinder with rotatable main handle in a cutting task. Human Factors, vol. 61, no. 7, p. 1112-1124, DOI:10.1177/0018720819827184.

[2] Alam, W., Mehmood, A., Ali, K., Javaid, U., Alharbi, S., Iqbal, J. (2018). Nonlinear control of a flexible joint robotic manipulator with experimental validation. Strojniški vestnik Journal of Mechanical Engineering, vol. 64, no. 1, p. 47-55, DOI:10.5545/sv-jme.2017.4786.

[3] Yadmellat, P., Shafer, A.S., Kermani, M.R. (2013). Design and development of a sin-gle-motor, two-DOF, safe manipulator. IEEE/ASME Transactions on Mechatronics, vol. 19, no. 4, p. 1384-1391, DOI:10.1109/TMECH.2013.2281598.

[4] Jian, G., Wang, Y. , Zhang, P., Xie, Y., Zhao, J. (2020). Analysis of lubricating performance for involute spur gear under vibration. Lubri-cation Science, vol. 32, no. 7, p. 344-357, D0l:10.1002/ Is.1507.

[5] Zhao, Y., Wei, W., Dong, X. (2008). Some problems on the 2DOF theory of gearing. Mechanism and Machine
Theory, vol. 43, no. 8, p. 1024-1037. D0l:10.1016/j. mechmachtheory.2007.07.002.

[6] Chen, Y.Z., Lv, Y.L., Ding, J., Chen, Z. (2013). Fundamental design equations for space curve meshing skew gear mechanism. Mechanism and Machine Theory, vol. 70, p. 175188, D0I:10.1016/J.mechmachtheory.2013.07.004.

[7] Chen, Y., Xiaoyong, X., Liang, L. (2009). A corrected equation of space curve meshing. Mechanism and Machine Theory, vol. 44, no. 7, p. 1348-1359, D0l:10.1016/j. mechmachtheory.2008.11.001.

[8] Litvin F.L., Demenego, A., Vecchiato, D. (2001). Formation by branches of envelope to parametric families of surfaces and curves. Computer Methods in Applied Mechanics \& Engineering, vol. 190, no. 35-36, p. 4587-4608, Dol:10.1016/ s0045-7825(00)00334-0.

[9] Kiekbusch, T., Sappok, D., Sauer, B., How-ard, I. (2011). Calculation of the combined torsional mesh stiffness of spur gears with two- and three-dimensional parametrical FE models. Strojniški vestnik - Journal of Mechanical Engineering, vol. 57, no. 11, p. 810-818, D0l:10.5545/sv-jme.2010.248.

[10] Guangjian, W., Lin, C., Li, Y., Shuaidong, Z. (2017). Research on the dynamic transmission error of a spur gear pair with eccentricities by finite element method. Mechanism \& Ma-chine Theory, vol. 109, p. 1-13, D0l:10.1016/j. mechmachtheory.2016.11.006.

[11] Chen, Y., Hu, Y., Lyu, Y., He, G. (2020). Development of a form milling method for line gear: principle, CNC machine, cutter, and testing. International Journal of Advanced Manufacturing Technology, vol. 107, no. 3-4, p. 1-11, D0l:10.1007/s00170019-04771-2.

[12] Chen, Y.Z., Yao, L. (2016). Design formulae for a concave convex arc line gear mechanism. Mechanical Sciences, vol. 7, no. 2, p. 209-218, Dol:10.5194/ms-7-209-2016.

[13] Chen, Y., Huang, H., Lv, Y. (2016). A var-iable-ratio line gear mechanism. Mechanism and Machine Theory, vol. 98, p. 151163, D0I:10.1016/j.mechmachtheory.2015.12.005.

[14] Chen, Y.Z., Lv, Y.L., Ding, J., Chen, Z. (2013). Fundamental design equations for space curve meshing skew gear mechanism. Mechanism and Machine Theory, vol. 70, p. 175188, D0I:10.1016/J.mechmachtheory.2013.07.004.

[15] Marimuthu, P., Muthuveerappan, G. (2013). Influence of pressure angle on load sharing based stresses in asymmetric normal contact ratio spur gear drives. Applied Mechanics and Materials, vol. 465-466, p. 1229-1233, D0l:10.4028/www. scientific.net/amm.465-466.1229.

[16] Ding, J., Chen, Y.Z., Lv, Y.L., Song, C. (2014). Positionparameter selection criterion for a helix-curve meshing-wheel mechanism based on sliding rates. Strojniški vestnik - Journal of Mechanical Engineering, vol. 60, no. 9, p. 561-570, DOl:10.5545/sv-jme.2013.1574.

[17] Litvin, F.L., Fuentes, A., Hayasaka, K. (2006). Design, manufacture, stress analysis, and experimental tests of lownoise high endurance spiral bevel gears. Mechanism and Machine Theory, vol. 41, no. 1, p. 83-118, D0l:10.1016/j. mechmachtheory.2005.03.001.

[18] Kulkarni, N., Gautham, B.P., Zagade, P., Panchal, J., Allen, J.K., Mistree, F. (2014). Exploring the geometry and material space 
in gear design. Engineering Optimization, vol. 47, no. 4, p. 561-577, DOI:10.1080/0305215x.2014.908868.

[19] Björling, M., Miettinen, J., Marklund, P., Lehtovaara, A., Larsson, R. (2015). The corre-lation between gear contact friction and ball on disc friction measurements. Tribology International, vol. 83, p. 114-119, D0l:10.1016/j.triboint.2014.11.007.

[20] Wu, X.T. (2009). Principle of Gearing. Jiaotong University Press, Xi'an. (in Chinese)

[21] Li, X., Sosa, M., Olofsson, U. (2015). A pin-on-disc study of the tribology characteris-tics of sintered versus standard steel gear materials. Wear, vol. 340-341, p. 31-40, D0l:10.1016/j. wear.2015.01.032.

[22] He, J., Wu, X., Cui, Y. (2004). Gearing principle and geometric design of conical in-volute gear pairs with crossed axes. Proceedings of the Institution of Mechanical Engineers. Part C: Journal of Mechanical Engineering Science, vol. 218, no. 12, p. 1517-1526, Dol:10.1243/0954406042690461.

[23] Chen, Y.Z. (2014). Line Gear. Science Press, Beijing. (in Chinese)
[24] Chen, Y.Z., Luo, L., Hu, Q. (2009). The contact ratio of a space-curve meshing-wheel transmission mechanism. Journal of Mechanical Design, vol. 131, no. 7, art. ID 074501, DOI:10.1115/1.3116343.

[25] Wang, G., Su, L., Zou, S. (2020). Uneven load contact dynamic modelling and trans-mission error analysis of a $2 \mathrm{~K}-\mathrm{V}$ reducer with eccentricity excitation. Strojniški vestnik Journal of Mechanical Engineering, vol. 66, no. 2, p. 91-104, DOI:10.5545/sv-jme.2019.6298.

[26] Yu, L., Wang, G., Zou, S. (2018). The ex-perimental research on gear eccentricity error of backlash-compensation gear device based on transmission error. International Journal of Precision Engineering and Manufacturing, vol. 19, p. 5-12, Dol:10.1007/s12541-018-0001-7.

[27] Guangjian, W., Lin, C., Li, Y., Shuaidong, Z. (2017). Research on the dynamic transmis-sion error of a spur gear pair with eccentricities by finite element method. Mechanism and Machine Theory, vol. 109, p. 1-13, D0l:10.1016/j. mechmachtheory.2016.11.006. 